\title{
Hyperlipidemia Caused by Voriconazole: A Case Report
}

This article was published in the following Dove Press journal:

Infection and Drug Resistance

\author{
Jiasheng $\mathrm{Wu}^{1,2, *}$ \\ $\mathrm{Na} \mathrm{Chen}^{3, *}$ \\ Yake Yao' \\ Jianying Zhou (D' \\ Hua Zhou (D) \\ 'Department of Respiratory and Critical \\ Care Medicine, The First Affiliated \\ Hospital, Zhejiang University School of \\ Medicine, Hangzhou, Zhejiang, 310003, \\ People's Republic of China; ${ }^{2}$ Department \\ of Respiratory and Critical Care \\ Medicine, Jiaxing Second Hospital, Jiaxing, \\ Zhejiang, 3 I 4000, People's Republic of \\ China; ${ }^{3}$ Department of Pharmaceutical, \\ The First Affiliated Hospital, Zhejiang \\ University School of Medicine, Hangzhou, \\ Zhejiang, 310003, People's Republic of \\ China
}

*These authors contributed equally to this work
Correspondence: Hua Zhou; jianying Zhou Email zhouhual@zju.edu.cn; zjyhz@zju.edu.cn

\begin{abstract}
Voriconazole has been widely used in clinical practice for nearly 20 years. The adverse reactions caused by voriconazole have been reported gradually, such as visual impairment, hepatotoxicity, skin rash. At present, there are few reports about triazole antifungal drugs causing the increase of triglyceride and total cholesterol. Thus, the present study reported a case of chronic pulmonary aspergillosis with significantly increased blood lipids after treatment with voriconazole. In this case, the patient's total cholesterol was normal, and triglyceride was 2.64 times of the upper limit of the reference value at the time of admission. On the 30th day after oral administration of voriconazole $200 \mathrm{mg}$ q12h, triglyceride and total cholesterol were 4.55 times and 3.31 times of the baseline levels, respectively, with the trough concentration of voriconazole of $6.6 \mu \mathrm{g} / \mathrm{mL}$. After 28 days of voriconazole withdrawal and itraconazole administration, triglyceride decreased to 1.45 times of baseline level and total cholesterol decreased to the normal range. After another 24 days of treatment with voriconazole $200 \mathrm{mg} \mathrm{q} 12 \mathrm{~h}$, triglyceride increased again to 3.25 times of the baseline level and cholesterol was within the normal range. At the same time, the trough concentration of voriconazole was $3.2 \mu \mathrm{g} / \mathrm{mL}$. After 14 days of treatment with voriconazole $100 \mathrm{mg} \mathrm{q} 12 \mathrm{~h}$, the triglyceride level recovered to the baseline level, with the trough concentration of voriconazole of $1.5 \mu \mathrm{g} / \mathrm{mL}$. The Naranjo's rating scale was used, the final score was 10 points, indicating that the causal relationship between voriconazole and dyslipidemia was positive, which was likely to be related to the trough concentration of voriconazole.
\end{abstract}

Keywords: voriconazole, chronic pulmonary aspergillosis, adverse reactions, hyperlipidemia

\section{Introduction}

Voriconazole (VRCZ) is the second generation of triazole antifungal drug that exerts antifungal effects by inhibiting 14 -sterol demethylation via cytochrome P450 in fungi to inhibit the biosynthesis of ergosterol. The common adverse reactions of VRCZ include hepatotoxicity and visual impairment, which are often related to the concentration of the drug. However, the effect of voriconazole on lipid metabolism has not been reported. Thus, the present study reported a case of chronic pulmonary aspergillosis (CPA) with significantly increased blood lipids after treatment with $\mathrm{VRCZ}$ and reviewed and analyzed the case of dyslipidemia caused by triazole antifungal drugs.

\section{Case Description}

A 44-year-old female patient, $148 \mathrm{~cm}$ height and $43 \mathrm{~kg}$ weight, was admitted to the First Affiliated Hospital, Zhejiang University School of Medicine for "blood in 
sputum for 11 months." Chest computed tomography (CT) of the patient showed dilatation of the bronchi in both lungs and nodular high-density shadows and air crescent sign in some cavities (Figure 1); hence, diagnosis of aspergilloma was considered. The patient was positive for specific IgG of Aspergillus fumigatus and galactomannan (GM) positive for alveolar lavage fluid in the right upper lobe. Subsequently, A. fumigatus was cultured, and the diagnosis was CPA. Voriconazole (VRCZ) tablets (200 mg every 12 hours) were taken orally from January 22, 2019. The patient had a history of rheumatoid arthritis and regularly administered leflunomide tablets $10 \mathrm{mg}$ QD for a long duration and had a history of sinus tachycardia, as well as metoprolol sustained-release tablets (47.5mg QD) for a long period.

Before administering VRCZ, the liver enzymes and the total cholesterol were normal, while the triglyceride was 2.64-fold of the upper limit of the reference value. After ingesting VRCZ tablets for 14 days, the liver enzyme levels were higher, while the blood lipids were similar to the baseline values. After administering the tablets for 30 days, the symptoms of blood in sputum disappeared. And the liver enzymes were normal while the blood lipids were significantly higher than the baseline values. Simultaneously, the trough concentration of VRCZ was $6.6 \mu \mathrm{g} / \mathrm{mL}$. Considering the possibility of hyperlipidemia caused by the drug, VRCZ was withdrawn, and itraconazole (200 mg every 12 hours) was administered.

After 28 days of itraconazole treatment, the liver enzymes and blood lipids recovered to baseline levels. While, the patient's symptoms of blood in sputum occurred.Then, the patient was given VRCZ tablets (200 mg every 12 hours) again.
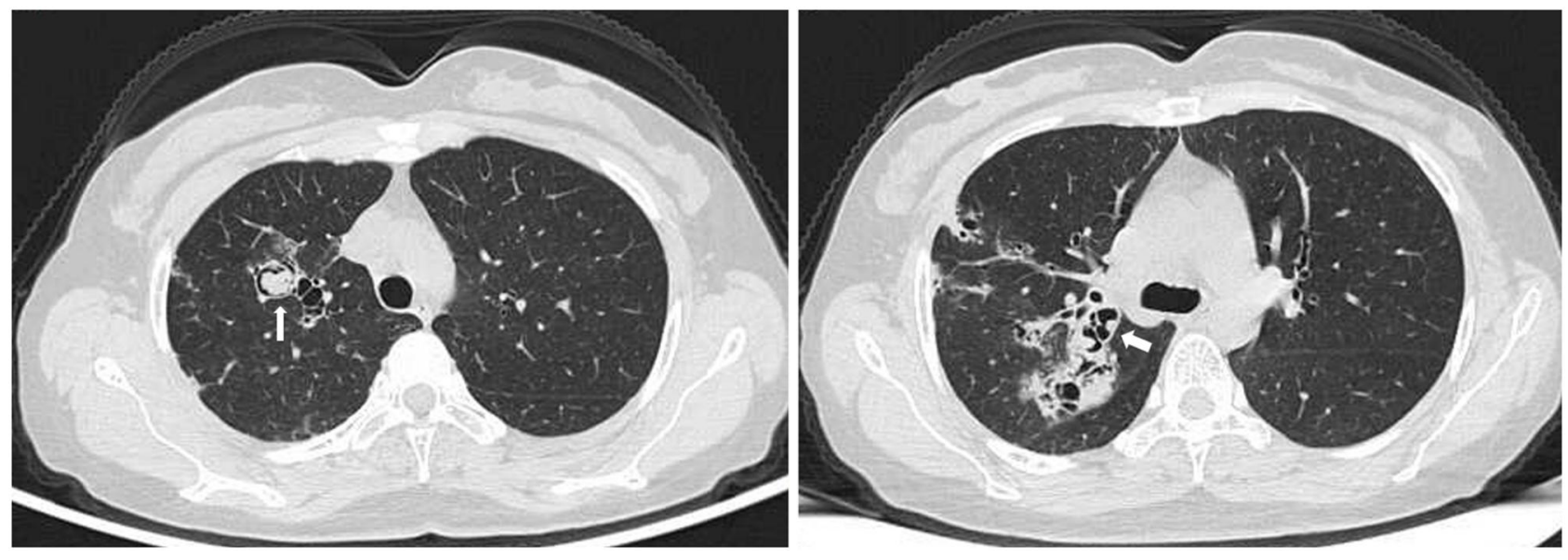

Figure I Chest CT image of the patient showed multiple dilatation of the bronchi with infection in the right lung. As shown by the arrow, aspergilloma can be seen in the dilated bronchus, showing air crescent sign. 
Table I The Specific Values of Liver Enzymes, Total Cholesterol and Triglyceride of the Patient During the Treatment

\begin{tabular}{|l|r|r|r|r|r|r|}
\hline Laboratory Indicators & $\begin{array}{l}\text { Day } \\
\mathbf{0}\end{array}$ & $\begin{array}{l}\text { Day } \\
\mathbf{1 4}\end{array}$ & $\begin{array}{l}\text { Day } \\
\mathbf{3 0}\end{array}$ & $\begin{array}{l}\text { Day } \\
\mathbf{6 0}\end{array}$ & $\begin{array}{l}\text { Day } \\
\mathbf{8 4}\end{array}$ & $\begin{array}{l}\text { Day } \\
\mathbf{1 3 0}\end{array}$ \\
\hline $\begin{array}{l}\text { Total cholesterol } \\
\text { (mmol/L) (3.14-5.86) }\end{array}$ & 3.6 & 3.65 & 11.93 & 4.59 & 4.66 & 3.26 \\
\hline $\begin{array}{l}\text { Triglycerides (mmol/L) } \\
(0.3-1.7)\end{array}$ & 4.5 & 4.51 & 20.51 & 6.56 & 14.64 & 4.84 \\
\hline $\begin{array}{l}\text { Aspartate } \\
\text { aminotransferase (U/L) } \\
(13-35)\end{array}$ & 11 & 18 & 28 & 19 & 16 & 15 \\
\hline $\begin{array}{l}\text { Alanine aminotransferase } \\
\text { (U/L) (7.40) }\end{array}$ & 22 & 54 & 16 & 10 & 12 & 7 \\
\hline $\begin{array}{l}\text { Trough concentration of } \\
\text { VRCZ ( } \mu \mathrm{gg} / \mathrm{mL})\end{array}$ & NA & NA & 6.6 & NA & 3.2 & 1.5 \\
\hline
\end{tabular}

Abbreviation: NA, not available.

itraconazole) is recommended for CPA to improve overall health status and respiratory symptoms, arrest haemoptysis and prevent progression. ${ }^{2} \mathrm{VRCZ}$ is the second generation of triazole antifungal drug that has been widely used in clinical practice for about 20 years. In addition to common adverse reactions, such as visual impairment, hepatotoxicity, and skin rash, ${ }^{3-5}$ unique reactions, such as phototoxic skin diseases and malignant tumors, periostitis, hair loss, alopecia, and nail changes, ${ }^{6}$ have also been found with long-term use. However, adverse reactions of hyperlipidemia have not yet been reported. Hong and $\operatorname{Lin}^{7}$ reported a case of dyslipidemia in a 48 -year-old female patient caused by itraconazole. In the second week after taking itraconazole, the patient showed elevated triglycerides and total cholesterol and normal alanine aminotransferase (ALT) and glutamic oxaloacetic transaminase (AST). The blood lipids recovered to normal 1-2 months after the withdrawal of itraconazole.

Presently, only one study ${ }^{7}$ has reported triazole antifungal drugs causing the increase in triglyceride and total cholesterol, and the mechanism is yet unclear. Studies have shown that among triazoles, VRCZ has the strongest affinity for steroid 24-hydroxylase (CYP46A1) and inhibits the conversion of cholesterol to 24-hydroxycholesterol in the brain. ${ }^{89}$ However, bile acids are generated from cholesterol through cholesterol $7 \quad \alpha$ hydroxylase (CYP7A1), which is a critical metabolic pathway of cholesterol in the human body. Therefore, the inhibition of cholesterol metabolism in the brain by voriconazole cannot explain the cause of elevated serum cholesterol in this patient. $^{10,11}$ In addition, cytochrome P4503A (CYP3A) is the only enzyme that converts retinoic acid to cis-9-retinoic acid, and cis-9-retinoic acid is the only ligand of retinoic acid X receptor (RXR). When combined, the upregulation of apoptosis and differentiation and proliferation of adipocytes is inhibited. After the inhibition of CYP3A, the synthesis of cis-9-retinoic acid is reduced, leading to a decrease in RXR activity, thus resulting in the decreased differentiation and the increase of apoptosis of peripheral adipocytes. ${ }^{12}$ As a CYP3A inhibitor, the commonly used ritonavir has a high incidence of

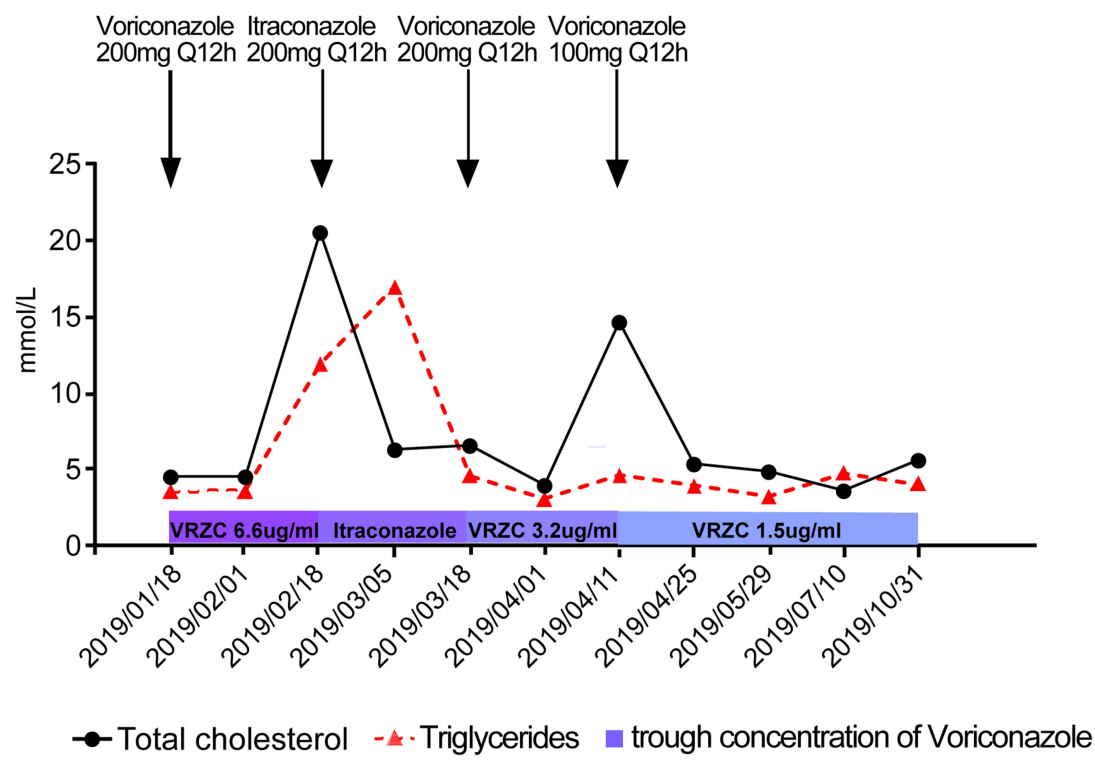

Figure 2 Changes in triglyceride, cholesterol, and trough concentration of VRCZ during treatment. 
hypertriglyceridemia, which is related to this mechanism. However, whether the abnormal increase of triglycerides is related to VRCZ as a CYP3A drug is yet to be verified. When the patient was given VRCZ again, and when the trough concentration of the drug was half of the first dose, serum cholesterol recovered to the baseline level, and serum triglyceride level also recovered to normal with the decrease in the trough concentration of VRCZ. However, current studies still cannot explain the causes of VRCZ-induced dyslipidemia, and further research is needed.

Although drug-induced hyperlipidemia is clinically common, VRCZ has not been reported previously to cause hyperlipidemia. Based on the data of this case, it is inferred that VRCZ-induced hyperlipidemia is a reversible concentration-dependent adverse reaction. In addition, the side effects of drug-induced hyperlipidemia require large scale population studies to observe whether it has implications for patients with cardiovascular and cerebrovascular disease especially in terms of incidence to stroke and myocardial infraction.

\section{Conclusion}

We clearly observed drug-induced hyperlipidemia caused by voriconazole in a patient with chronic pulmonary aspergillosis. The level of triglycerides and cholesterol was positively correlated with the trough concentration of voriconazole. Therapeutic drug monitoring and blood lipid level monitoring were both important during the use of voriconazole.

\section{Ethics Approval and Consent for Publication}

This study has been reviewed and approved by the Research Ethics Committee of the First Affiliated Hospital of Zhejiang University (ref\#2020-1502). The patient provided informed consent for publication of the clinical details including lung CT images, and written informed consent was obtained.

\section{Author Contributions}

All authors made substantial contributions to conception and design, acquisition of data, or analysis and interpretation of data; took part in drafting the article or revising it critically for important intellectual content; agreed to submit to the current journal; gave final approval of the version to be published; and agree to be accountable for all aspects of the work.

\section{Funding}

No funding was granted.

\section{Disclosure}

The authors declare that they have no conflicts of interest.

\section{References}

1. Naranjo CA, Busto U, Sellers EM, et al. A method for estimating the probability of adverse drug reactions. Clin Pharmacol Ther. 1981;30 (2):239-245. doi:10.1038/clpt.1981.154

2. Denning DW, Cadranel J, Beigelman-Aubry C, et al. Chronic pulmonary aspergillosis: rationale and clinical guidelines for diagnosis and management. Eur Respir J. 2016;47(1):45-68. doi:10.1183/ 13993003.00583-2015

3. Dolton MJ, McLachlan AJ. Voriconazole pharmacokinetics and exposure-response relationships: assessing the links between exposure, efficacy and toxicity. Int J Antimicrob Agents. 2014;44(3):183-193. doi:10.1016/j.ijantimicag.2014.05.019

4. Levine MT, Chandrasekar PH. Adverse effects of voriconazole: over a decade of use. Clin Transplant. 2016;30(11):1377-1386. doi: $10.1111 /$ ctr. 12834

5. Purkins L, Wood N, Greenhalgh K, et al. Voriconazole, a novel widespectrum triazole: oral pharmacokinetics and safety. $\mathrm{Br} J$ Clin Pharmacol. 2016;56(s1):2-9. doi:10.1046/j.1365-2125.2003.01993.x

6. Benitez LL, Carver PL. Adverse effects associated with long-term administration of azole antifungal agents. Drugs. 2019;1-21. doi:10.1007/s40265-019-01127-8

7. Hong L, Lin W. A case report of elevated serum cholesterol and triglyceride induced by itraconazole. Chin J Clin Pharm Ther. 2010;08:886-887.

8. Björkhem I, Lütjohann D, Breuer O, Sakinis A, Wennmalm A. Importance of a novel oxidative mechanism for elimination of brain cholesterol. Turnover of cholesterol and 24(S)-hydroxycholesterol in rat brain as measured with $18 \mathrm{O} 2$ techniques in vivo and in vitro. $J$ Biol Chem. 1997;272(48):30178-30184. doi:10.1074/ jbc.272.48.30178

9. Lund EG, Xie C, Kotti T, Turley SD, Dietschy JM, Russell DW. Knockout of the cholesterol 24-hydroxylase gene in mice reveals a brain-specific mechanism of cholesterol turnover. $J$ Biol Chem. 2003;278:22980-22988. doi:10.1074/jbc.M303415200

10. Liu H, Pathak P, Boehme S, et al. Cholesterol $7 \alpha$-hydroxylase protects the liver from inflammation and fibrosis by maintaining cholesterol homeostasis. J Lipid Res. 2016;57(10):1831-1844. doi:10.1194/ jlr.M069807

11. Li T, Chiang JYL. Bile acids as metabolic regulators. Curr Opin Gastroenterol. 2015;31(2):159-165. doi:10.1097/MOG.000000 0000000156

12. Zanetti HR, Roever L, Goncalves A, et al. Human immunodeficiency virus infection, antiretroviral therapy, and statin: a clinical update. Curr Atheroscler Rep. 2018;20(2):9. doi:10.1007/s11883-018-0708-z 


\section{Publish your work in this journal}

Infection and Drug Resistance is an international, peer-reviewed openaccess journal that focuses on the optimal treatment of infection (bacterial, fungal and viral) and the development and institution of preventive strategies to minimize the development and spread of resistance. The journal is specifically concerned with the epidemiology of antibiotic resistance and the mechanisms of resistance development and diffusion in both hospitals and the community. The manuscript management system is completely online and includes a very quick and fair peerreview system, which is all easy to use. Visit http://www.dovepress.com/ testimonials.php to read real quotes from published authors. 